\title{
SISTEMAS ADESIVOS
}

\author{
ADHESIVE SYSTEMS
}

Sérgio Spezzia

Cirurgião Dentista e Mestre em Ciências pela Escola Paulista de Medicina Universidade Federal de São Paulo.

\section{Autor Principal:}

\section{Sérgio Spezzia}

Email: sergio.spezzia@unifesp.br 


\section{Resumo}

Sistemas adesivos constam do agrupamento de monômeros resinosos dotados de diferenciadas características, bem como são compostos por solventes orgânicos e diluentes. Almeja-se com o recurso da Odontologia Restauradora obter-se adesividade dos materiais odontológicos resinosos aos dentes por intermédio do uso dos sistemas adesivos. O objetivo deste artigo foi averiguar acerca da utilização dos sistemas adesivos nos procedimentos odontológicos. Dispõem-se de vários materiais odontológicos para uso, englobando a categoria dos sistemas adesivos, concomitantemente existem disponibilizadas técnicas para utilização voltadas particularmente a cada material. O selecionamento de determinado sistema adesivo para emprego clínico, visando proceder ao seu uso satisfatoriamente deve ocorrer de forma consciente e deve basear-se nas características apresentadas por cada material. Pode-se classificar os sistemas adesivos em convencionais ou etch-and-rinse e em autocondicionantes ou self-etch. Adesivos multimodais ou universais constituem uma outra categoria disponibilizada para uso, que possui a propriedade de poder ser empregado, fazendo-se uso da técnica autocondicionante ou convencional. A escolha correta do sistema adesivo para utilização clínica, levando em consideração as particularidades do elemento dental que será restaurado tende a propiciar desfecho restaurador satisfatório.

Palavras-chave: Adesividade. Adesivos. Esmalte Dentário. Dentina.

Keywords: Adhesiveness. Adhesives. Dental Enamel. Dentin. 


\section{INTRODUÇÃO}

A Odontologia Restauradora caminha para a exclusão do emprego de preparações cavitárias extensas e para a adoção de condutas minimamente invasivas, incluindo a opção pela escolha de recursos para tratamento funcionais, estéticos e com cunho conservador, advindo do incremento dos sistemas adesivos e de materiais adesivos disponibilizados para uso. Almeja-se com o recurso da Odontologia Restauradora obter-se adesividade dos materiais odontológicos resinosos aos dentes por intermédio do uso dos sistemas adesivos (MENEZES FILHO, PF, et al., 2003; DUBINSK, P, et al., 2005; ALEX, G, 2015).

Utilizam-se técnicas restauradoras inovadoras, nesse contexto, principalmente no que tange ao recurso clínico da Odontologia Estética, onde faz-se uso dos sistemas adesivos inevitavelmente, buscando união entre dente e o material odontológico empregado. O papel dos sistemas adesivos na Odontologia Estética foi fundamentalmente importante para que fosse possibilitada a execução de restaurações estéticas diretas dotadas de boas propriedades (PASHLEY, DH \& TAY, FR, 2001; CARVALHO, RM, 2004).

Os atendimentos realizados na área da Dentística utilizam técnicas adesivas, entretanto, alguns problemas são evidenciados quando da realização desses procedimentos, uma vez que a adesividade proporcionada em esmalte e em dentina difere, devido às características histológicas intrínsecas (OSORIO, R, et al., 2009; GEERTS, SO, et al., 2010; NAGPAL, R, et al., 2011).

Relacionado mais especificamente a forma como procede a adesão nos elementos dentais, sabe-se que em esmalte existe estabelecimento de adesão satisfatória, assegurando bom desfecho clínico restaurador. Em contrapartida quando a adesão achase relacionada com a dentina, têm-se adesão heterogênea, que é efetivada por intermédio da hibridização do tecido. Nesse contexto, o emprego dos sistemas adesivos depende das diferentes características histológicas existentes nos tecidos de esmalte e de 
dentina (SILVERSTONE, LM, et al., 1975; AL-EHAIDEB, A \& MOHAMMED, H, 2000; DE MUNCK, J, et al., 2005; XAVIER, CCG, 2005).

Sistemas adesivos constam do agrupamento de monômeros resinosos dotados de diferenciadas características, bem como são compostos por solventes orgânicos e diluentes (CARVALHO, RM, 2004).

O objetivo deste artigo foi averiguar acerca da utilização dos sistemas adesivos nos procedimentos odontológicos.

\section{REVISÃO DE LITERATURA}

Dispõem-se de vários materiais odontológicos para uso, englobando a categoria dos sistemas adesivos, concomitantemente existem disponibilizadas técnicas para utilização voltadas particularmente a cada material. O selecionamento de determinado sistema adesivo para emprego clínico, visando proceder ao seu uso satisfatoriamente deve ocorrer de forma consciente e deve basear-se nas características apresentadas por cada material (MARTINS, GC, et al., 2008; BARBOSA, KGN \& D’ AVILA, S, 2012).

Algumas situações clínicas podem requerer o uso dos sistemas adesivos, tais como: para selamento de fóssulas e fissuras; cimentação de pinos intra-radiculares; para restaurar lesões não cariosas; fixação de braquetes em Ortodontia e para promover adesividade nas restaurações indiretas, entre outras (REIS, AF, et al., 2006).

A preparação dentária realizada em procedimentos operatórios ocasiona a formação de uma camada denominada de smear layer. Relacionado aos procedimentos que visam obtenção de adesividade, a smear layer atua influenciando o possível desfecho restaurador a ser obtido. Os cuidados empreendidos, visando resolução desse inconveniente oriundo da presença do smear layer levaram a instituição de uma classificação dos sistemas adesivos baseada na forma como age o material frente a essa camada de resíduos. Alguns sistemas adesivos retiram por completo a camada de smear layer, enquanto outros excluem parcialmente essa camada (ARAÚJO, MAM \& BOTTINO, MA, 1998; VAN MEERBEEK, B, et al., 1998; TAY, FR \& PASHLEY, D H, 2001). 
Baseado na maneira como procede o tratamento dessa smear layer, pode-se classificar os sistemas adesivos em sistemas adesivos que alteram a smear layer, mantendo-a no transcorrer da obtenção de adesividade; sistemas adesivos que excluem a smear layer por intermédio da utilização de condicionamento ácido e sistemas que promovem o dissolvimento da smear layer (VAN MEERBEEK, B, et al., 1998).

Pode-se classificar os sistemas adesivos em convencionais ou etch-and-rinse e em autocondicionantes ou self-etch. Nos convencionais, a princípio ocorre o condicionamento ácido, visando obtenção posterior da adesividade. Estes adesivos podem ser configurados como de três passos, quando ocorre emprego do primer, do agente adesivo e do condicionamento ácido disponibilizados cada qual em seu frasco e de dois passos, quando têm-se condicionamento ácido e primer mais agente adesivo coadjuvados num frasco. Nesse tipo de sistema adesivo ocorre a remoção por completo do smear layer da superfície via condicionamento ácido. Já nos autocondicionantes o tratamento ácido acha-se inserido no primer. Estes adesivos podem estar configurados para uso em um passo e em dois passos. Autocondicionantes podem ser encontrados disponibilizados em dois frascos, sendo um frasco de adesivo e outro do primer que contém o ácido ou podem ser encontrados em somente um frasco, que contém propriedades de primer, ácido e de adesivo. Os sistemas autocondicionantes promovem dissolvimento de forma parcial da smear layer (MILIA, E, et al., 1999; AGUIAR, TR, et al., 2008; GIACHETTI, L, et al., 2008; GIANINI, RJ, et al., 2009; DAVID, HP, et al., 2011; VAN MEERBEEK, B, et al., 2011; MUNOZ, MA, et al., 2013).

Adesivos multimodais ou universais constituem uma outra categoria disponibilizada para uso, que possuem a propriedade de poderem ser empregados, fazendo-se uso da técnica autocondicionante ou convencional (MENA-SERRANO, A, et al., 2013; MUNOZ, MA, et al., 2013; MARCHESI, G, et al., 2014; PERDIGÃO, J, et al., 2014; PERDIGÃO, J, et al., 2014; WAGNER, A, et al., 2014).

Os sistemas adesivos podem ser classificados no contexto geral, levando em conta a quantidade de frascos disponibilizados; sua composição, se contendo água, acetona ou álcool e a forma como procede sua polimerização, entre outras características apresentadas (GRAZZIOTIN, JC, 2002). 


\section{DISCUSSÃO}

No cotidiano dos atendimentos odontológicos o emprego de sistemas adesivos prima por requerer a execução de procedimentos mais simplificados a serem efetuados em curto espaço de tempo ou mais rapidamente, devido ao fato devem ocorrer adequações e incremento ou aperfeiçoamento na produção dos sistemas adesivos. A evolução tecnológica permite que sistemas adesivos sejam introduzidos para uso, podendo cobrir tais requisitos (VAN MEERBEEK, B, et al., 2003; VAN MEERBEEK, B, et al., 2011).

No cômputo geral, pode-se preferir materiais odontológicos para emprego clínico que possuam propriedades satisfatórias quanto a resistência e estética e que concomitantemente possuam adesividade aos tecidos mineralizados do dente (CARVALHO, RM, 2004).

$\mathrm{Na}$ dentina afligida pela cárie dentária existem inconvenientes para realizar posteriormente a restauração, envolvendo interferência na realização do condicionamento ácido e na penetração dos monômeros resinosos em dentina, o que repercute na adesividade (WANG, Y, et al., 2007).

Almeja-se fornecer um sistema adesivo para utilização tanto em dentina como em esmalte, que mostre-se condizente com as propriedades antagônicas desses tecidos, baseado nesse fato existem inúmeros e diferenciados sistemas adesivos disponíveis para emprego clínico (GIACHETTI, L, et al., 2008; GIANINI, RJ, et al., 2009).

Condutas odontológicas que fazem utilização dos adesivos usam de ácidos, solventes ou de monômeros, os quais alteram os aspectos fisiológicos e morfológicos dos tecidos de esmalte e dentina (VAN MEERBEEK, B, et al., 1998; CARVALHO, RM, et al., 2003; VAN MEERBEEK, B, et al., 2003; CARVALHO, RM, 2004; GUTHER, NS, et al., 2006).

Os componentes vários dos diversos sistemas adesivos; a forma como ocorre sua ação nos dentes e sua aplicabilidade clínica, entre outros fatores influem decisivamente na obtenção ou não de um desfecho favorável das restaurações (CARVALHO, RM, 2004; MARTINS, GC, et al., 2008; BARBOSA, KGN \& D’ AVILA, S, 2012). 
Convém salientar que os sistemas adesivos podem receber classificação voltada para as gerações desses materiais que foram sendo introduzidas com o passar dos anos, tendendo sempre a haver incremento nas gerações mais novas quando comparadas as antecessoras, quanto às suas características propiciadas frente à camada de smear layer, seja inexistindo sua remoção ou executando sua retirada parcial ou totalmente, seja pela quantidade de passos clínicos executados (ARAÚJO, MAM \& BOTTINO, MA, 1998; VAN MEERBEEK, B, et al., 1998; TAY, FR \& PASHLEY, D H, 2001).

\section{CONCLUSÃO}

A escolha correta do sistema adesivo para utilização clínica, levando em consideração as particularidades do elemento dental que será restaurado tende a propiciar desfecho restaurador satisfatório.

\section{REFERÊNCIAS}

1. Menezes Filho PF, Braz R, Silva Souza Jr. MH. Avaliação in vitro da microinfiltração marginal em restaurações classe II, empregando resinas condensáveis com quatro bases estendidas. JBD, 2003; 2(5):37-42.

2. Dubinsk P, Cardoso SA, Hoeppner MG. Avaliação das causas das substituições de restaurações nas disciplinas de dentística II e clínica integrada do curso de Odontologia da UNIPAR - Campus Umuarama. Publ UEPG Ci Biol Saúde, 2005; 11(1):7-14.

3. Alex G. Universal adhesives: the next evolution in adhesive dentistry? Compend Contin Educ Dent, 2015; 36(1):15-26.

4. Pashley DH, Tay FR. Aggressiveness of contemporary self-etching adhesives. Part II: etching effects on unground enamel. Dent Mat, 2001; 17(5):430-44.

5. Carvalho RM. Sistemas Adesivos: fundamentos para aplicação clínica. Biodonto, 2004; 2(1):1-86.

6. Osorio R, Monticelli F, Moreira MA, Osorio E, Toledano M. Enamel-resin bond durability of self-etch and etch \& rinse adhesives. Am J Dent, 2009; 22(6):371-5.

REVISTA FLUMINENSE DE ODONTOLOGIA - ANO XXVI - № 54 - Julho / Dezembro 2020 
7. Geerts SO, Seidel L, Albert AI, Gueders AM. Microleakage after thermo cycling of three self-etch adhesives under resin-modified glass ionomer cement restorations. Int $\mathbf{J}$ Dent, 2010; 2010:728453

8. Nagpal R, Manuja N, Tyagi SP, Singh UP. In vitro bonding effectiveness of self-etch adhesives with different application techniques: A microleakage and scanning electron microscopic study. J Conserv Dent, 2011; 14(3):258-63.

9. Silverstone LM, Saxton CA, Dogon IL, Fejerskov O. Variation in the pattern of acid etching of human dental enamel examined by scanning electron microscopy. Caries Res, 1975; 9(5):373-87.

10. Al-Ehaideb A, Mohammed H. Shear bond strength of "one 2. bottle" dentin adhesives. J Prosthet Dent, 2000; 84(4):408-12.

11. De Munck J, Van Landuyt K, Peumans M, Poitevin A, Lambrechts P, Braem M, et al. A critical review of the durability of adhesion to tooth tissue: methods and results. $\mathbf{J}$ Dent Res, 2005; 84(2):118-32.

12. Xavier CCG. Análise "in vitro" da resistência de união da resina composta à dentina tratada com diferentes sistemas adesivos. [Tese]. Araraquara: Faculdade de Odontologia de Araraquara - Universidade Estadual Paulista Júlio de Mesquita Filho, 2005.

13. Martins GC, Franco APGO, Godoy EP, Maluf DR, Gomes JC, Gomes OMM. Adesivos dentinários. RGO, 2008; 56(4):429-36.

14. Barbosa KGN, D’Avila S. Sistemas adesivos dentários em lesões cervicais não cariosas: decisão clínica baseada em evidências científicas. Arq Bras Odontol, 2012; $8(2): 30-8$.

15. Reis AF, Cassoni A, Kirihata M, Sapata ASP, Atui RAFL, Pereira PNL, et al. Degradação das interfaces resina-dentina: uma revisão da literatura. Rev Odontol UNESP, 2006; 35(3):191-9.

16. Araújo MAM, Bottino MA. Como melhor explorar os adesivos dentinários nos procedimentos restauradores. In: Gonçalves EAN, Feller C. Atualização na clínica odontológica: a prática da clínica geral. São Paulo: Artes Médicas, 1998, p. 61-81.

17. Van Meerbeek B, Perdigão J, Lambrechts P, Vanherle G. The clinical performance of adhesives. J Dent, 1998; 26(1):1-20. 
18. Tay FR, Pashley DH. Agressiveness of contemporary self-etching systems. I: depth of penetration beyond dentin smear layers. Dent Mat, 2001; 17:296-308.

19. Milia E, Lallal MR, Garcia-Godoy F. In vivo effect of a "self-etching primer" on dentin. Am J Dent, 1999; 12(4):167-71.

20. Aguiar TR, Di Francescantonio M, Ambrosano GMB. Avaliação da resistência de união de novos sistemas adesivos ao esmalte e dentina. Rev Bras Odontol, 2008; 65(2):177-80.

21. Giachetti L, Scaminaci Russo D, Bambi C, Nieri M, Bertini F. Influence of operator skill on microleakege of total etch and self etch bonding systems. J Dent, 2008; 36(1):49-53.

22. Gianini RJ, do Amaral FL, Flório FM, Basting RT. Effects of dentine moisture on the permeability of total-etch and one-step self-etch adhesives. J Dent, 2009; 37(9):6919.

23. David HP, Franklin RT, Lorenzo B, Leo T, Ricardo M. Carvalho F, et al. State of the art etch-and-rinse adhesives. Dent Mater, 2011; 27:1-16.

24. Van Meerbeek B, Yoshihara K, Yoshida Y, Mine A, De Munck J, Van Landuyt KL. State of the art of self-etch adhesives. Dent Mater, 2011;27(1):17-28.

25. Munoz MA, Luque I, Hass V, Reis A, Loguercio AD, Bombarda NHC. Immediate bonding properties of universal adhesives to dentine. J Dent, 2013; 41(5):404-11.

26. Mena-Serrano A, Kose C, De Paula EA, Tay LY, Reis A, Loguercio AD. A new universal simplified adhesive: 6-month clinical evaluation. J Esthet Rest Dent, 2013; 25(1):55-69.

27. Marchesi G, Frassetto A, Mazzoni A, Apolonio F, Diolosa M, Caderano M, et al. Adhesive performance of a multi-mode adhesive system: 1-year in vitro study. J Dent, 2014; 42(5):603-12.

28. Perdigão J, Kose C, Mena-Serrano AP, De Paula EA, Tay LY, Reis A, et al. A new universal simplified adhesive: 18-month clinical evaluation. Oper Dent, 2014; 39(2):113-27.

29. Perdigão J, Munoz MA, Sezinando A, Luque-Martinez IV, Staichak R, Reis A, et al. Immediate adhesive properties to dentin and enamel of a universal adhesive associated with a hydrophobic resin coat. Oper Dent, 2014; 39(5):489-99.

REVISTA FLUMINENSE DE ODONTOLOGIA - ANO XXVI - № 54 - Julho / Dezembro 2020 
30. Wagner A, Wendler M, Petschelt A, Belli R, Lohbauer U. Bonding performance of universal adhesives in different etching modes. J Dent, 2014; 42(7):800-7.

31. Grazziotin JC. Adesivos Auto Condicionantes. Especialização em Dentística Restauradora. [Monografia]. Florianópolis: Universidade Federal de Santa Catarina, 2002.

32. Van Meerbeek B, De Munck J, Yoshida Y, Inoue S, Vargas M, Vijay P, et al. Adhesion to enamel and dentin: current status and future challenges. Oper Dent, 2003; 28(3):215-35.

33. Wang Y, Spencer P, Walker MP. Chemical profile of adhesive/caries-affected dentin interfaces using Raman microspectroscopy. J Biomed Mater Res, 2007; 81(2):279-86.

34. Carvalho RM, Mendonça JS, Santiago SL, Silveira RR, Garcia FC, Tay FR, et al. Effects of HEMA/solvent combinations on bond strength to dentin. J Dent Res, 2003; 82(8):597-601.

35. Guther NS, Maia R, Panzeri FC, Pardini LC. A resistência adesiva ao esmalte e dentina: sistemas adesivos total-etch e self-etch - estágio atual. JBD, 2006; 5(17):87-91. 